\title{
Clinical Applications of Botulinum Toxin in Patients with Dysphagia
}

\author{
Jung-Hae Cho (D) \\ Department of Otorhinolaryngology-Head and Neck Surgery, College of Medicine, The Catholic University of Korea, Seoul, Korea
}

$$
\text { 삼킴 장애 환자에서 보튤리눔 독소의 임상적 적용 }
$$

조 정 해

가톨릭대학교 의과대학 이비인후과학교실

Dysphagia may result from dysfunction of any of the components involved in the complex neuromuscular interaction of swallowing. Hyperfunction of any of the muscles involved in swallowing is a frequent cause of dysphagia. The cricopharyngeus muscle (CPM) is a key component of the upper esophageal sphincter. Cricopharyngeus muscle dysfunction (CPD) refers to the muscle's failure to appropriately and completely relax or expand during deglutition. A variety of disease processes may cause CPD and accurate diagnosis is paramount for appropriate treatment. In appropriately selected patients, intervention at the CPM may yield significant improvement in dysphagia. Interventions include nonsurgical, pharyngoesophageal segment dilatation, botulinum toxin (BoNT) injection, and criccopharyngeal myotomy. Injections of BoNT in patients with CPD have been reported to result in marked relief of dysphagia. Different techniques for instilling BoNT into the CPM have been described. Awake, in-office CPM BoNT injection with electromyography and/or fluoroscopic or ultrasound guidance is performed transcervically or via flexible endoscopy. Operative CPM BoNT injection involves rigid laryngoscopy and esophagoscopy with direct visualization of the CPM. BoNT should be prepared in low-volume, high-concentration dilutions to minimize the potential for undesired diffusion of the toxin. The effects of BoNT occur within weeks of injection and typically last up to 5 or 6 months.

Keywords Dysphagia; Botulinum toxin; Cricopharyngeal muscle.

\section{서 론}

삼킴 장애(dysphagia)는 삶의 질과 전반적인 건강 행태에 가장 큰 영향을 미치는 질 환 중 하나이다. 삼킴 장애는 크게 구강인두 삼킴 장애(oropharyngeal dysphagia)와 식 도 삼킴 장애(esophageal dysphagia)로 나눌 수 있다. 구강인두 삼킴 장애는 음식물 자 체를 삼키는 시작 시점에 문제가 있는 것이고, 식도 삼킴 장애는 음식물은 넘겼으나 이 후에 음식물이 식도에 정체되어 더 이상 진행이 안 되어 걸린 경우를 말한다. 이와 같은 삼킴 장애는 삼킴 과정 중 관여하는 다양한 근육들의 과도한 연축(spasm)으로 발생할 수 있다. 윤상인두근(cricopharyngeus muscle)은 상부식도 괄약근(upper esophageal

\author{
Received October 29, 2018 \\ Revised December 19, 2018 \\ Accepted April 5, 2019

\section{Corresponding Author} \\ Jung-Hae Cho, MD, PhD \\ Department of Otorhinolaryngology- \\ Head and Neck Surgery, \\ College of Medicine, \\ The Catholic University of Korea, \\ St. Vincent's Hospital, \\ 93 Jungbu-daero, Paldal-gu, \\ Suwon 16247, Korea \\ Tel +82-31-249-8306 \\ Fax+82-31-257-3752 \\ E-mail jhchomd@catholic.ac.kr

\section{ORCID iD} \\ Jung-Hae Cho (D) \\ https://orcid.org/0000-0001-9904-7869
}

\author{
This is an Open Access article distributed \\ under the terms of the Creative \\ Commons Attribution Non-Commercial \\ License (https://creativecommons.org/ \\ licenses/by-nc/4.0) which permits \\ unrestricted non-commercial use, \\ distribution, and reproduction in any \\ medium, provided the original work is \\ properly cited.
}


sphincter)의 한 부분이며 이것이 삼킴 과정 중 적절히 이완 되거나 확장되지 못하는 질환이 윤상인두근 장애(cricopharyngeal dysfunction or achalasia)이며 구강인두 삼킴 장애의 가장 흔한 원인이 된다. 또한 식도 하부 괄약근(lower esophageal sphincter)의 이완불능증(achalasia)이 식도 삼 킴 장애의 중요한 원인이 된다. 다양한 원인 및 기저 질환에 의해 삼킴 장애가 발생하므로 이에 따라 치료를 결정을 해야 한다. 일반적으로 재활 운동 치료, 수술, 약물 치료가 있으며 특히 삼킴 과정 중 관여하는 괄약 근육(sphincter muscle)의 강직이 주 원인일 경우에는 보튤리눔 독소(botulinum neurotoxin)를 이용하는 것이 좋은 대안으로 제시되고 있다. 본 종설에서는 삼킴 장애 환자에서 보튤리눔 독소를 적용할 수 있는 대상을 알아 보고 이를 적절하게 임상에서 사용하는 방 법에 대해 알아보고자 한다.

\section{본 론}

보튤리눔 독소 주입술은 구강인두 삼킴 장애와 식도 삼킴 장애에서 널리 사용되고 있다. 보튤리눔 독소 주입술은 적절 한 평가를 통해 정확한 진단으로 잘 선택된 환자에서 유용하 게 이용될 수 있다. 성인뿐만 아니라 소아에서도 적용이 가능 하며 특수한 상황 즉 과도한 침 흘림을 스스로 관리하지 못하 여 재발성 폐렴이 빈번히 발생하는 환자나 후두전적출술 후 삼킴 장애 환자에서도 유용하게 적용할 수 있다. 따라서 본 론에서는 이와 관련하여 현재까지 보고되고 있는 보튤리눔 독소 주입술의 적응과 유용성 및 시술 방법에 대해 알아 보 고자 한다.

\section{윤상인두부전증(Cricopharyngeal achalasia)}

\section{환자에서 보튤리눔 독소의 임상적 적용}

상부식도 괄약근은 하인두에서 근위부 식도에 이르는 부 위로 약 $2.5 \sim 4.5 \mathrm{~cm}$ 정도의 길이이다. 이 중 윤상인두근은 하 부 인두수축근(inferior pharyngeal constrictor muscle)과 경부 식도근 사이의 이행부에 위치하고 있다. ${ }^{1)}$ 휴식기에는 수
축되어 식도로부터 인두로 역류를 방지하지만 연하기에는 이 완되어 열리게 된다. 만일 이와 같은 작용이 일어나지 않아 윤 상인두근의 수축이 지속될 경우 심한 삼킴 장애를 유발한다. 여러 원인으로(Table 1) 윤상인두근 장애(dysfunction) 또는 부전증(achalasia)이 발생하며 특히 이 부위에만 단독으로 장 애(isolated cricopharyngeal dysfunction)가 올 수도 있다. 임상 증상으로는 음식물 섭취 시 코로 넘어 오거나 반복적인 흡인이 있으며 내시경상에서 하인두에 점액이나 침이 저류되 면 본 질환을 의심할 수 있다. 진단은 임상 증상뿐만 아니라 비디오투시경하 삼킴 검사(videofluoroscopic swallowing study), 근전도, 고해상도 압력 검사(high resolution manometry)를 통해 내릴 수 있다. 통상적인 치료로는 재활 치료, 내 시경적 확장술, 윤상인두근 절제술, 윤상인두근 내 보튤리눔 독소 주입술 등이 있다. 이와 관련하여 발표된 논문들의 체계 적 고찰에 따르면 치료의 성공률은 윤상인두근 절제술이 가 장 높으나 합병증 비율 또한 가장 높았다. ${ }^{2}$ 반면 보튤리눔 독 소 주입술은 상대적으로 성공률이 낮았지만 가장 낮은 합병 증을 보고하여 환자의 상태를 고려하여 시술의 안정성과 침 습성을 고려할 때 보튤리눔 독소 주입술은 넓은 적응증을 가 져서 여러 치료 방법 중 우선적으로 선택할 수 있을 것으로 예상이 된다. 1994년 Schneider 등 ${ }^{3)}$ 이 처음으로 윤상인두 부 전증 환자에서 보튤리눔 독소 주입을 보고하였다. 이 치료의 가장 좋은 적응증은 윤상인두근 단독 장애(isolated cricopharyngeal dysfunction)에 의한 삼킴 장애 환자이다. ${ }^{4)}$ 그 외 다른 장애가 있더라도 상대적으로 윤상인두근의 강직성이 확 인되는 삼킴 장애도 적응증이 될 수 있다. 보튤리눔 독소를 윤상인두근에 주입하는 방법은 접근 방식에 따라 경피적 접 근법과 내시경적 접근법으로 크게 나눌 수 있다. ${ }^{1)}$ 경피적 접 근법에는 가장 일반적 방법인 근전도 유도하 주입술이 있으며 이외에도 CT, 비디오투시경하, 초음파 등을 이용하는 방법이 있다. 한편 내시경적 접근법은 전신 마취 후 후두현수현미경 하에서 직접 관찰하면서 근육 내로 주입하게 된다(Fig. 1). 보 튤리눔의 용량은 환자 상황에 따라 다양하게 적용할 수 있으 나 일반적으로 20 100 IU을 사용한다. ${ }^{1)}$ 치료 반응을 확인하

Table 1. Causes of cricopharyngeal dysfunction ${ }^{1)}$

\begin{tabular}{lllll} 
Neurological/neuromuscular & Inflammatory/autoimmune & \multicolumn{1}{c}{ Neoplastic } & \multicolumn{1}{c}{ Metabolic } & Iatrogenic \\
Stroke & Polymyositis & Hypopharyngeal cancer & Hyperthyroidism & Skull base resection \\
Traumatic brain injury & Inclusion body myositis & Thyroid cancer & Myxedema & Radiotherapy \\
Parkinson' disease & Scleroderma & Esophageal cancer & Diabetes & Resection and neural injury \\
Amyotrophic lateral sclerosis & Diphtheria & & Carotid endarterectomy \\
Muscular dystroy & Caustic ingestion & & & \\
& Reflux disease & & & \\
& Dermatomyositis & & & \\
& & & & \\
\hline
\end{tabular}


고 부작용을 최소화하기 위해 첫 치료에서는 평상적인 용량 보다 적은 양을 주입하고 치료 반응이 좋아 재치료 시에는 보 다 많은 양을 주입하는 것이 좋다. 주입 후 보튤리눔이 후두 내 근육으로 확산되어 성대마비와 같은 부작용을 유발할 수 있으므로 고농도의 보다 적은 생리식염수를 사용하는 것을 추천한다. 즉, $1 \sim 2 \mathrm{cc}$ 의 생리식염수에 $100 \mathrm{IU}$ 을 희석하여 사 용하며 주입 부위는 상부 식도 괄약근의 후방부와 양측 측방 부 등 3 부위에 나누어 주입하게 된다.

최근 Wang 등 ${ }^{5}$ 이 초음파 유도하 보튤리눔 독소 주입술을 증례 보고하였으며 본 저자도 수술 후 발생한 윤상인두근 단 독 장애 환자에서 초음파 유도하에 직접 윤상인두근을 확인 하면서 보튤리눔 독소를 주입할 수 있어 그 유용성을 확인하 였다.

\section{소아 삼킴 장애 환자에서 보튤리눔 독소의 적용}

소아 환자에서 윤상인두근 장애가 의심되면 비디오투시경 하 삼킴 검사를 통해 확진할 수 있고 성인 환자의 치료에서와 같이 보튤리눔 독소 주입술, 내시경하 확장술, 근절제술 등의 치료법을 적용하여 모두 유의한 성공률을 보인다고 하였다. ${ }^{6}$ Scholes 등ㄱ은 보튤리눔 독소를 윤상인두근 장애로 인하여 삼킴 장애가 있는 소아에 적용하여 좋은 결과를 보고하고 있 다. 삼킴 장애가 있는 소아 환자들은 대부분 신경학적 이상을 지니고 있었으며 이들 환자에서 전신마취 후 내시경하에서 $1.4 \sim 5.1 \mathrm{IU} / \mathrm{kg}$ 의 보튤리눔 독소를 주입하여 6 명의 환자 중 5 명에서 치료 성공률을 보였다고 보고하였다.

\section{과도한 침 흘림 환자에서 보튤리눔 독소의 사용}

과도한 타액과 이를 적절히 스스로 관리할 수 없는 환자에 서는 타액 자체가 지속적으로 흡인이 되어 삼킴 장애에서 발 생할 수 있는 흡인성 폐렴이 문제가 된다. 타액 분비를 억제 하기 위해서 초음파 유도하에 보튤리눔 독소를 타액선 내로

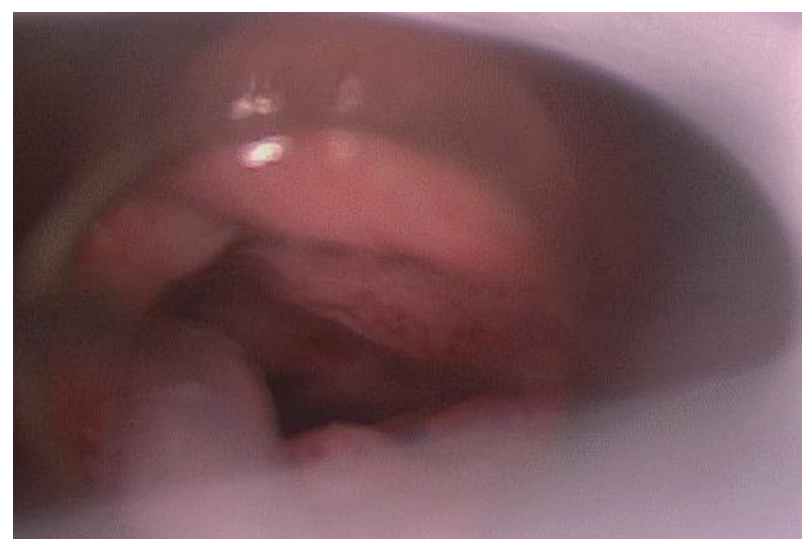

Fig. 1. Endoscopic view during suspension laryngoscope showing upper esophageal sphincter.
주입하였을 때 장기적으로 좋은 효과가 보고 되고 있다. ${ }^{8)}$ 전 체 주타액선 내 보튤리눔 독소 주입은 보통 $250 \mathrm{IU}$ 이 적정 용 량으로 생각되며 특히 이하선 내에 주입 시에는 안면 신경의 일시적 마비가 올 수 있으므로 주의가 필요하다. 일반적으로 초음파 유도하에 이하선을 4등분하여 4부위에 분할 주입하 여 전체 $75 \mathrm{IU}$ 용량이 되게 한다(Fig. 2). 반면, 악하선은 악설 골근을 기준으로 2 등분하여 2 부위에 각각 주입하여 악하선 에 약 $50 \mathrm{IU}$ 을 주입하는 것을 권유하고 있다. ${ }^{8)}$ 신경학적 장애 에 의한 연하 장애가 있으면서 과도한 타액으로 인한 흡인성 폐렴의 위험성이 높은 환자들에게 우선적으로 적용할 수 있다.

\section{후두전적출술 후 삼킴 장애 환자에서 보튤리눔}

\section{독소의 적용}

후두전적출술 환자가 수술 후 구강 식이가 원활이 되다가 갑자기 발성과 고체 성괴의 음식이 넘기기 힘들다면 인두식 도분절의 연축(spasm of pharyngoesophageal segment)을 의심할 수 있다. 인두수축근의 과도한 강직 때문에 발생하며 이로 인하여 삼킴 장애뿐만 아니라 발성 장애도 함께 동반되 게 된다. 보튤리눔 독소를 비디오 투시경하 또는 강직형 식도 내시경하에 $100 \mathrm{IU}$ 를 주입하면 높은 성공률을 보이게 된다.9) 또한 저자는 초음파 유도하에 보튤리눔 독소를 주입하여 실 시간으로 인두식도분절을 확인할 수 있어 환자의 불편성을 최소한으로 하면서 효과적으로 원하는 부위에 주입할 수 있

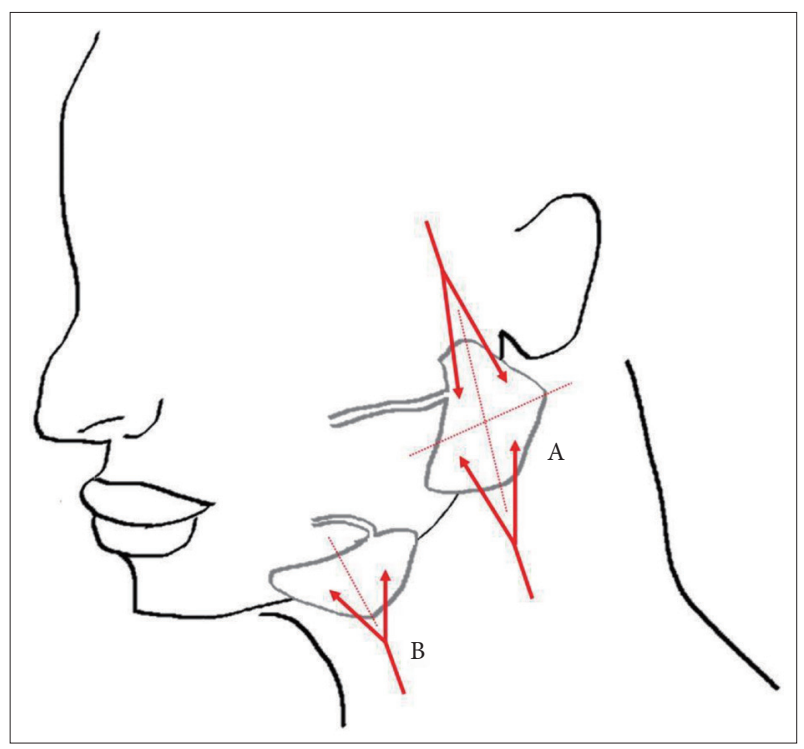

Fig. 2. Injection sites in parotid and submandibular glands. Parotid gland: following ultrasound-guided identification of the parotid gland, the gland was divided into four quadrants. A total of 75 unit BoNT can be injected into four quadrants (A). Submandibular gland: following ultrasound-guided identification of the submandibular gland between the anterior and posterior bellies of the digastric muscle under the mandible, a total of 50 unit BoNT can be injected into two quadrants (B). BoNT: botulinum toxin. 

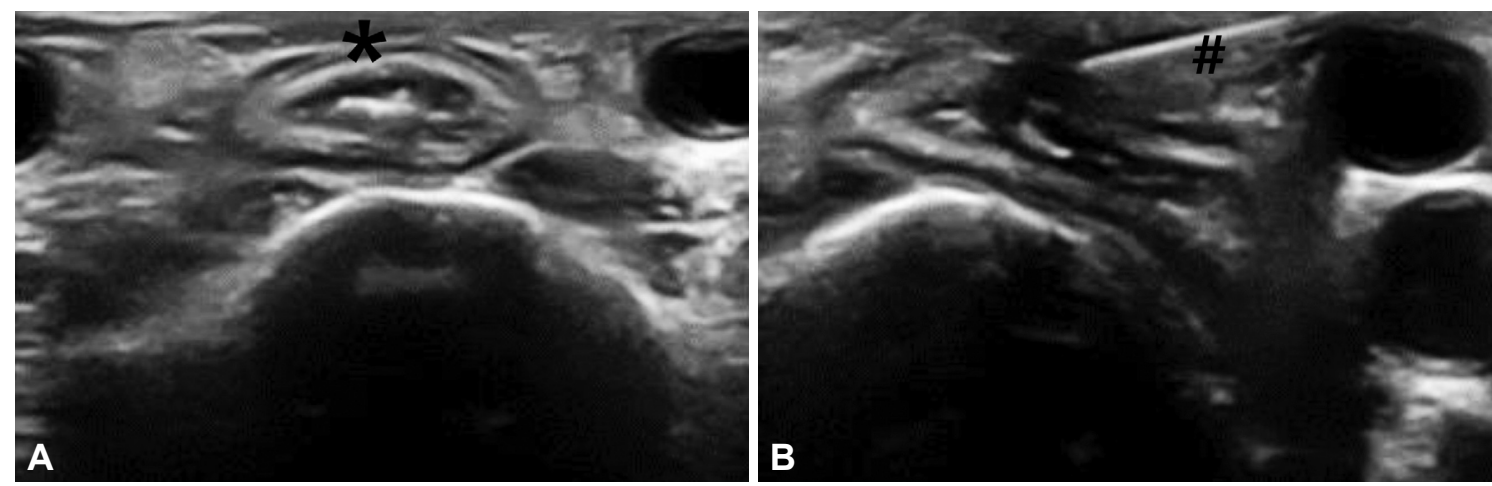

Fig. 3. Ultrasound guided injection to pharyngoesophageal segment in patient with total laryngectomy. Transverse ultrasound imgage showing esophagus $\left(^{*}\right)(A)$. US guided botulinum toxin injectin with 25 gauge needle (\#) (B).

는 방법을 선택하고 있다(Fig. 3). 한편 후두전적출술 후 음성 재활을 위해 기관식도천자 후에 성대 보형물(voice prosthesis)를 삽입하게 되는데 식도의 강직이나 협착이 있으면 음식 물이 내려가지 못하면서 식도 내에 음압이 발생하여 음식물이 보형물 사이로 역류하여 삼킴 장애 및 흡인성 폐렴을 유발하 게 된다. 이와 같은 경우에 Mullan 등이는 강직이 되어 있는 식 도 근육내로 보튤리눔 독소를 주입하여 이 문제를 해결할 수 있는 방안을 제시하였다.

\section{식도 운동 장애 환자에서 보튤리눔 독소의 적용}

식도이완불능증(esophageal achalasia)은 식도의 가장 빈 번하고 중요한 운동성 장애이다. 하부식도 괄약근의 이완이 저하되어 발생되면 환자는 고체 성분의 음식뿐만 아니라 액 체 성분에도 삼킴 장애를 호소한다. 식도이완불능증의 등급 에 따라 치료 대상을 결정을 해야 하며 치료 대안으로는 풍선 확장술, 근절제술, 내시경하 보튤리눔 독소 주입술이 있다. ${ }^{11}$ 내시경하 보튤리눔 독소 주입은 $5 \mathrm{cc}$ 의 생리 식염수에 $100 \mathrm{IU}$ 의 보튤리눔을 희석하여 하부식도 괄약근 부위 약 5 군데에 주입을 하게 된다. 현재 미국에서는 첫 치료로 가장 많이 선 택되고 있는 방법이며 단일 주입으로 치료 반응률은 1 년 후 약 $40.6 \%$ 까지로 보고되었다. ${ }^{12)}$

\section{삼킴 장애에서 보튤리눔 주입술 시 주의 사항 및 결과}

보튤리눔 독소는 삼킴 장애 발병 후 약 1주일부터 최소한 4개월 이내에 주입을 하는 것이 결과에 좋은 것으로 알려져 있다. 목표로 한 부위 외 인접 부위로 확산을 방지하기 위해 적은 생리 식염수로 희석하여 고농도로 주입하는 것이 합병 증을 줄이고 효과를 높일 수 있다. 첫 주입 시에는 일반적으 로 적은 용량을 사용하는 것이 합병증을 줄일 수 있다. 보고 에 따르면 단기간의 효과는 약 70 100\%로 보고되며 평균 작 용 기간은 약 7개월이다. 합병증으로는 보튤리눔 독소가 다른 해부학적 위치로 확산되어 생기는 경우가 있는데 윤상인두근
에 과도하게 주입하거나 주위의 후두 내 근육으로 주입할 경 우 성대 마비와 삼킴 장애를 더 악화시키는 것이 보고되었다.

\section{결 론}

삼킴 장애 환자를 치료하기 위해서는 적절한 평가를 통하 여 장애의 원인을 파악하여 이에 맞는 치료가 필요하다. 윤상 인두근 장애로 인한 삼킴 장애에서 윤상인두근 내로 보튤리 눔 독소 주입은 안전하면서 효과적으로 알려져 가장 널리 사 용된다. 근육 내로 정확히 주입하기 위해 다양한 방법이 적용 되고 있으며 환자와 시술자의 상황에 따라 적절하게 선택되어 야 한다. 그러나 보튤리눔 독소의 적절한 용량, 농도, 주입 간 격에 대해서는 논란이 있으므로 보편적인 가이드라인을 정립 하기 위해서는 향후 전향적 연구가 필요하다.

중심 단어: 삼킴 장애, 보튤리눔 독소, 윤상인두근.

Acknowledgments

None.

Conflicts of Interest

The author has no financial conflicts of interest.

\section{REFERENCES}

1. Kuhn MA, Belafsky PC. Management of cricopharyngeus muscle dysfunction. Otolaryngol Clin North Am 2013;46(6):1087-99.

2. Kocdor P, Siegel ER, Tulunay-Ugur OE. Cricopharyngeal dysfunction: a systematic review comparing outcomes of dilatation, botulinum toxin injection, and myotomy. Laryngoscope 2016;126(1):135-41.

3. Schneider I, Thumfart WF, Pototschnig C, Eckel HE. Treatment of dysfunction of the cricopharyngeal muscle with botulinum A toxin: introduction of a new, noninvasive method. Ann Otol Rhinol Laryngol 1994;103(1):31-5.

4. Moerman MB. Cricopharyngeal Botox injection: indications and technique. Curr Opin Otolaryngol Head Neck Surg 2006;14(6):431-6.

5. Wang YC, Shyu SG, Wu CH, Wang TG. Ultrasound-guided injection of botulinum toxin for cricopharyngeal dysphagia. Am J Phys Med Rehabil 2018;97(10):e102-3.

6. Huoh KC, Messner AH. Cricopharyngeal achalasia in children: indi- 
cations for treatment and management options. Curr Opin Otolaryngol Head Neck Surg 2013;21(6):576-80.

7. Scholes MA, McEvoy T, Mousa H, Wiet GJ. Cricopharyngeal achalasia in children: botulinum toxin injection as a tool for diagnosis and treatment. Laryngoscope 2014;124(6):1475-80.

8. Barbero P, Busso M, Tinivella M, Artusi CA, De Mercanti S, Cucci A, et al. Long-term follow-up of ultrasound-guided botulinum toxin-A injections for sialorrhea in neurological dysphagia. J Neurol 2015;262 (12):2662-7

9. Chao SS, Graham SM, Hoffman HT. Management of pharyngoesoph- ageal spasm with Botox. Otolaryngol Clin North Am 2004;37(3):55966

10. Mullan GP, Lee MT, Clarke PM. Botulinum neurotoxin for management of intractable central leakage through a voice prosthesis in surgical voice restoration. J Laryngol Otol 2006;120(9):789-92.

11. Tack J, Zaninotto G. Therapeutic options in oesophageal dysphagia. Nat Rev Gastroenterol Hepatol 2015;12(6):332-41.

12. Campos GM, Vittinghoff E, Rabl C, Takata M, Gadenstätter M, Lin F, et al. Endoscopic and surgical treatments for achalasia: a systematic review and meta-analysis. Ann Surg 2009;249(1):45-57. 